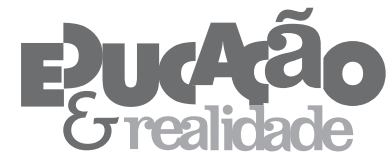 \\ A Lei no 10.639/03 e o Epistemicídio: relações e embates
}

\author{
Elisabete Figueroa dos Santos' \\ Eliane Aparecida Toledo Pinto ${ }^{11,}$ III \\ Andréia Melanda Chirinéa"
}

'Centro Universitário Central Paulista (UNICEP), São Carlos/SP - Brasil

"Universidade do Sagrado Coração (USC), Bauru/SP - Brasil

"'Fundação Educacional Municipal de Ibitinga (FEMIB), Ibitinga/SP - Brasil

RESUMO - A Lei no 10.639/03 e o Epistemicídio: relações e embates. O texto visa discutir os fatores dificultadores e facilitadores para a implementação da Lei $n^{\circ} 10.639 / 03$, que coloca a necessidade de se trabalhar conteúdos de História e Cultura Afro-brasileiras no ensino. Passada mais de uma década de sua promulgação, nota-se que sua aplicação é atravessada por uma série de controvérsias. Neste contexto, propõe-se pensar currículo e proposta político-pedagógica entendendo que excelência educacional é uma questão que não deve ser descolada da noção de equidade. Para que seja efetivado um ensino pluriversal deve-se antes problematizar as artimanhas do epistemicídio na efetivação ou contestação de conteúdos no processo de ensino-aprendizagem.

Palavras-chave: Lei no 10.639/03. História e Cultura Afro-Brasileira. Epistemicídio. Negros.

ABSTRACT - The Law 10.6239/03 and Epistemecide: relations and shocks. The text aims to discuss factors that complicate or facilitate the implementation of Law 10.639/03, which places the need to work contents of Afro-Brazilian History and Culture in education. It has passed more than a decade of its promulgation, but we note that its application is crossed by a series of controversies. Therefore, it is proposed to think curriculum and politicalpedagogical proposal by understanding that educational excellence is a matter that should not be detached from the notion of equity. In order to release one pluriversal education, we shall discuss before the wiles of epistemicide in the execution or defense of contents in the teaching-learning process.

Keywords: Law 10.639/03. Afro-Brazilian History and Culture. Epistemicide. Black People.

Educação \& Realidade, Porto Alegre, v. 43, n. 3, p. 949-967, jul./set. 2018. 949 http://dx.doi.org/10.1590/2175-623665332 


\section{Introdução}

Podemos considerar que os primeiros quinze anos do século XXI viu florescer importantes medidas no que se refere à busca pela garantia de direitos de negros e negras, sobretudo no campo da Educação. Como exemplo, pode-se citar a promulgação das leis: 10.639/2003 (Brasil, 2003), que coloca a necessidade de se trabalhar conteúdos de História e Cultura Afro-brasileiras no ensino público e privado brasileiro; a 12.288/2010 (Brasil, 2010), que rege sobre o estabelecimento do Estatuto da Igualdade Racial brasileiro; e a 12.711/2012 (Brasil, 2012), que dispõe sobre a reserva de cota para estudantes negros no ensino superior. Todas essas são medidas essenciais para se pensar e programar medidas de combate às desigualdades étnico-raciais em detrimento de negros(as) no Brasil.

Não obstante, nota-se que passada mais de uma década da promulgação da lei no 10.639/03, a efetivação e a difusão desta medida caminham a passos demasiadamente lentos, de modo que se torna relevante analisar o curso dado ao processo de implementação dessa lei. $\mathrm{O}$ presente ensaio pretende inserir-se neste debate, discutindo as ausências e silenciamentos verificados historicamente para questões orientadas a partir de matrizes africanas e afro-brasileiras que são, em grande medida, sustentadas pelas práticas epistemicidas, que deslegitimam a possibilidade de serem tais referenciais válidos e potencialmente geradores e fomentadores de conhecimento.

Para tanto, inicialmente traçamos uma breve caracterização da fenda existente entre brancos e negros no acesso e permanência nas diferentes etapas do ensino; em seguida situamos suscintamente o histórico de lutas e reivindicações de políticas de promoção da igualdade racial na educação brasileira. Na sequência, lançamos mão da noção de epistemicídio para analisar os arranjos forjados na área do saber e que garantem a invalidação de formas de conhecimento associadas a grupos não dominantes; e, por fim, com base em alguns estudos que foram construídos durante esta primeira década de vigência da lei, fazemos alguns apontamentos acerca do que essa literatura relata como fatores dificultadores e facilitadores da implementação da lei, bem como suas controvérsias.

\section{Negros(as) na Educação: do apagamento físico}

A sociedade brasileira é composta por uma diversidade étnico-racial ${ }^{1}$ que caracteriza sua população e cultura. Contudo, é notável que essa mesma diversidade não é representada com equidade nas instâncias de construção e propagação de saber. Isto porque em sociedades compostas por diferentes grupos raciais e atravessadas pelo racismo, como é o caso do Brasil, a raça exerce funções simbólicas valorativas e estratificadoras (Fernandes, 1978). Os postos de produção e veiculação de conhecimento constituem-se a partir desta mesma realidade. 
No que diz respeito à expressão da categoria raça no campo da educação, números e indicadores de levantamentos diversos demonstram que ainda existem desigualdades acentuadas entre pessoas brancas e negras (pretas e pardas). Nesse sentido, Fúlvia Rosemberg e colaboradoras realizaram uma série de estudos (Rosemberg, 1987; 1990; 1991; 1995; Rosemberg; Pinto; Negrão, 1986; Rosemberg; Pinto, 1987; 1997) que buscou caracterizar a participação de negras e negros na educação brasileira, com ênfase para análises de frequência, assiduidade e distribuição espacial na rede escolar do estado de São Paulo, sobretudo para as séries iniciais. As pesquisadoras apontam que as crianças negras tendem a repetir o ano escolar com maior frequência que as brancas. Além disso, discute-se que as crianças negras evadem com mais frequência e mais cedo do sistema escolar, além de experimentarem mais afastamentos e retornos para a escola. Dessa forma, constatou-se que a trajetória escolar de crianças negras sofre mais interferências e reveses que as de crianças brancas. As dificuldades que elas encontram para manterem-se assíduas aos bancos escolares indicam, entre outras coisas, que o sistema escolar tem sido ineficiente em manter crianças negras assíduas ao ambiente escolar, evidenciando a conflituosa relação estabelecida entre as crianças negras e os parâmetros sustentados pelo sistema educacional.

Ao analisarmos os dados acerca da ocorrência de analfabetismo entre diferentes grupos raciais, verifica-se que entre os analfabetos absolutos acima de 15 anos, 7,1\% são brancos e 16,9\%, negros. Enquanto $18,4 \%$ de brancos são classificados como analfabetos funcionais, $64,6 \%$ dos negros podem receber a mesma caracterização (Instituto Brasileiro de Geografia e Estatística, 2005).

Analisando as taxas de participação de brancos e negros nos diferentes níveis de escolarização, constata-se que no que toca a educação infantil, 10,3\% das crianças brancas de 0 a 6 anos têm acesso à escola, ao passo que, crianças pretas correspondem a 9,5\% e pardas, $8,3 \%$ (Instituto Brasileiro de Geografia e Estatística, 2000). Além disso, de acordo com dados coletados pelas PNADs (Pesquisa Nacional de Análise por Domicílio) no período de 2004 a 2012, pretos e pardos apresentaram taxas de matrícula superiores às de brancos para o Ensino Fundamental. Contudo, de acordo com o Educacenso, levantamento baseado em dados da PNAD 2013, em relação à faixa do ensino médio, observou-se uma queda acentuada da frequência líquida na média brasileira, que esteve no patamar de $55,1 \%$. No entanto, ao observar os dados desagregados por cor/raça, é possível notar que $63,7 \%$ da população branca e $49,3 \%$ da população negra na faixa etária correspondente frequentam o ensino médio. Ou seja, a frequência de negros é consideravelmente inferior à de brancos. Situação que é agravada quando se toma como referência o ensino superior, faixa para a qual a taxa de frequência líquida brasileira corresponde a $16,3 \%$. Para os brancos a taxa constatada é de $23,4 \%$, pouco mais que o dobro da verificada para negros e negras, cuja taxa é de 10,7\% (Instituto Brasileiro de Geografia e Estatística, 2014).

Educação \& Realidade, Porto Alegre, v. 43, n. 3, p. 949-967, jul./set. 2018. 
Os dados apresentados esboçam a situação de desigualdade verificada para o acesso e permanência de brancos e negros nos diferentes níveis do ensino brasileiro. Como indicam os estudos acima mencionados, à medida que se avança nos níveis de ensino, maior é a presença de brancos e menor a de negros. A constatação deste quadro suscitou nas últimas décadas a reivindicação e a defesa de políticas públicas que buscam combater tais desigualdades raciais. Assim, os parâmetros tradicional e pretensiosamente universalistas de educação passaram a ser rediscutidos por entidades do poder público, uma vez que, apesar das diversas iniciativas e ensaios, prevalece a histórica marginalização de certos grupos em meio à educação brasileira, de modo que muito ainda cabe a se fazer para que haja a reversão das desigualdades seculares.

\section{Medidas de Enfrentamento ao Racismo no Ensino: lutas e reivindicações}

Educação de qualidade tem sido bandeira de luta de movimentos sociais, organizações da sociedade civil, gestores e diversos outros atores que lidam direta ou indiretamente com a questão educacional. No entanto, sabe-se que qualidade educacional é um conceito polissêmico, em disputa, ainda que essa disputa seja timidamente explicitada. Ou seja, excelência educacional é uma questão que não pode ser pensada e avaliada descolada da noção de equidade.

Foi a partir do século XX que o movimento negro passou a se articular em torno das próprias organizações, entidades ou sociedades negras, que tinham como horizonte aumentar sua margem de ação e influência na sociedade, tendo em vista o combate à discriminação racial e a construção de mecanismos de valorização da raça negra (Gonçalves; Silva, 2000; Santos; Scopinho, 2016). Tal iniciativa procurava ainda nas primeiras décadas dos anos de 1900, garantir educação para os negros a partir de propostas próprias, dada a desassistência do Estado. Nesse ínterim, destaca-se a atuação da Frente Negra Brasileira (FNB), a mais relevante entidade construída pelo movimento negro após a abolição (Domingues, 2008). Durante a década de 1930, a FNB edificou iniciativas voltadas à instrução e educação da população negra. Sob responsabilidade da FNB esteve, por exemplo, a implementação da primeira escola com acentuada estrutura pedagógica voltada para negros. A educação era entendida por essa entidade como uma arma inalienável na luta contra o racismo e suas discriminações correlatas.

O movimento negro, a partir da década de 1970, travou enorme esforço para desvelar e elucidar as desigualdades raciais, todavia nem sempre com articulação e estratégia mais efetivas. Posto isso, a década de 1990 foi marcada pela redefinição de sua prática e teve em vista a reivindicação de políticas públicas para a garantia dos direitos básicos de negras e negros. Dessa forma, o movimento negro, com o decorrer do tempo, expandiu suas exigências e expectativas acerca da educação para a população negra. Passou-se, então, a reivindicar ações afirmativas voltadas à inclusão de pessoas negras em setores sociais até então 
dominados, sobretudo, pela parcela populacional branca e nos quais a participação negra era desigual.

A partir de então, muitos projetos de lei de cunho antirracista foram propostos e debatidos. Cabe ressaltar os textos que integram a coletânea organizada pelo então deputado federal Abdias do Nascimento e intitulada Combate ao Racismo, de 1983/84. Nesses documentos, além de inúmeros projetos referentes à punição da discriminação racial e à alteração de currículos, estão englobadas várias formulações jurídicas, explicitamente vinculadas à ação afirmativa para negros: a proposição de reserva de vagas no mercado de trabalho ( $40 \%$ do total); a oferta de bolsas de estudos universitários; a instituição de meios concretos que garantissem o ingresso no Instituto Rio Branco; e outros que fazem parte da gama de formulações então em discussão (Contins; Sant'Anna, 1996).

Um projeto de lei que previa a aplicação de cota mínima (primeiro de $10 \%$, depois de $20 \%$ ) para grupos étnico-raciais socialmente discriminados, em instituições de ensino superior, foi proposto por Carlos Minc. Grande foi sua repercussão no interior do movimento negro, de modo a provocar discussões e posicionamentos controversos e atingir nos anos iniciais de 1990 a Assembleia Legislativa do estado do Rio de Janeiro. Ainda em 1993, o então deputado federal Florestan Fernandes (PT/SP) propôs um Projeto de Emenda Constitucional cujo objetivo era garantir a oferta de bolsas de estudos para crianças, jovens e adultos negros e a senadora Benedita da Silva apresentou dois projetos de lei com o formato de cotas étnico-raciais: um definia cotas de $10 \%$ para estudantes negros e índios em instituições de ensino superior e o outro a inclusão de um mínimo de $40 \%$ de artistas e profissionais negros nas produções das emissoras de televisão, filmes e peças publicitárias (Contins; Sant'Anna, 1996).

As primeiras respostas efetivas no que toca à efetivação de medidas de ações afirmativas para a população negra no ensino superior vieram na primeira década dos anos 2000. As universidades estaduais do Rio de Janeiro e da Bahia, UERJ e UNEB, respectivamente, foram convocadas pelos governos de seus estados, a adotar cotas em seus cursos de graduação em favor de negras e negros. A Universidade de Brasília (UnB), entre 2000 e 2002, realizou vários debates sobre a política de cotas para o ingresso de negros. Em 2001, a UnB reconheceu, estatisticamente, a desigualdade racial em relação aos estudantes: dos 26 mil estudantes, apenas $2 \%$ eram negros (Nery, 2008) e foi a primeira universidade federal brasileira a instituir o sistema de cotas para estudantes negros, em junho de 2004, após cinco anos de debates (Santos; Scopinho, 2016).

Diante desse quadro e identificando-se as repercussões psicossociais que podem advir do apagamento das atuações e contribuições de parte da população, devido especificamente aos racismos (tais como dificuldades atitudinais, déficits na autoestima, entre outras), entidades e movimentos sociais começaram a fazer ecoar a requisição do tratamento adequado de conteúdos de história e cultura africanas e afro- 
-brasileiras no contexto educacional. A partir de suas reivindicações têm sido construídas propostas e ferramentas de intervenção nas desigualdades raciais. Podemos destacar a promulgação da lei no 10.639/03 em 09 de janeiro de 2003 (Brasil, 2003) - que altera a Lei de Diretrizes e Bases da Educação Nacional (LDB) e inclui no currículo oficial dos estabelecimentos de ensino básico das redes pública e privada do país, a obrigatoriedade de estudo da temática História e Cultura Afro-brasileira. Tanto esta lei, como as Diretrizes Curriculares Nacionais para a Educação das Relações Étnico-Raciais e para o Ensino de História e Cultura Afro-Brasileira e Africana (Brasil, 2004), aprovadas posteriormente em março de 2004 pelo Conselho Nacional de Educação mostram-se importantes medidas de ação afirmativa, ao responder a um conjunto de reivindicações históricas de pessoas e grupos que há quase cinco séculos pautam a necessidade da efetivação de políticas públicas capazes de transformar a nossa realidade, ainda racista e excludente.

No que concerne às desigualdades étnico-raciais, a disputa é dada em duas esferas: no campo da esfera pública, pela concorrência direta por políticas eficazes e medidas de garantia de direitos e, no campo do simbólico, atrelando negros a determinados lugares sociais e representações. Contudo, é preciso registrar que o apagamento de temas e perspectivas africanas e afro-brasileiras impede que sejam, efetivamente, vislumbrados os mecanismos que constroem e mantêm as disparidades raciais no Brasil.

\section{Do Apagamento Simbólico: em pauta o epistemicídio}

No Brasil, a limitação do alcance de negras e negros aos locais de acesso, divulgação e compartilhamento dos saberes oficializados acompanhou o estabelecimento de um sistema de descrédito aos modelos de conhecimento de africanos, indígenas e seus descendentes. Tal cerceamento organizou a sociedade brasileira para estabelecer critérios culturais e raciais para a produção e incorporação de conhecimento. Nesse contexto, é necessário ponderar sobre a construção de narrativas oficiais e de referências identitárias a partir de vieses que desqualificam culturas, conhecimentos e cosmovisões, com base numa ótica hierarquizante que, no limite, rechaça epistemologias não hegemônicas. Logo, tudo que não é o mesmo é tomado como causa para a contestação da validade de saberes; para crivar visões de mundo; e para pontuar quais devem ser o sujeito e o objeto do conhecimento.

A invalidação de práticas, modos de ser, idiomas e saberes dos povos sob dominação europeia configurou uma forma de refutar a legitimidade de cosmovisões africanas e de povos nativos, taxadas como bárbaras e primitivas, constituindo, desse modo, o que se tem denominado epistemicídio. Não se nega unicamente as formas de conhecimento vinculadas à empiria dos povos tradicionais, rechaça-se, em última instância, a própria possibilidade de serem esses grupos detentores de formas úteis de saber e tecnologias que fujam aos domínios, compreensões e doutrinas eurocentradas. É necessário questionarmos, assim, 
por que nas discussões sobre as origens e formas de elaboração do saber, acerca das quais somos formalmente informados, prevalecem proposições que eliminam do seu arcabouço de reflexões coerentes a centralidade do contexto cultural e político para a produção, reprodução e contestação do conhecimento.

Santos (1996) aponta que a dominação europeia não se limitou a territórios físicos, mas também simbólicos; o que gerou a marginalização/invalidação de formas de conhecimento vinculadas aos sujeitos diferentes. Para este autor, o genocídio que tantas vezes caracterizou a expansão europeia foi também um epistemicídio:

\begin{abstract}
Eliminaram-se povos estranhos porque tinham formas de conhecimento estranho porque eram sustentados por práticas sociais e povos estranhos. O epistemicídio foi muito mais vasto que o genocídio, porque ocorreu sempre que se pretendeu subalternizar, subordinar, marginalizar [...] (Santos, 1996, p. 104).
\end{abstract}

O extermínio de saberes africanos e afro-brasileiros é garantido por meio de arranjos que cerceiam a produção e divulgação de conhecimentos negros por meio de diferentes artimanhas: pela contestação e invalidação de epistemologias e formas de conhecimentos africanos; por meio da escassez de negras e negros nos postos de saber institucionalizados (branqueamento da educação); através da ausência/escassez de conteúdos relacionados às questões negras/africanas nos currículos oficiais e trabalhados de formas coerentes; e, por fim e, como consequência das artimanhas anteriores, pelo não desenvolvimento de tecnologias, soluções e conhecimentos voltados para as demandas da população negra.

Esse apagamento dos negros e conteúdos a eles relativos está na base das dificuldades verificadas pela população negra para manter-se cativa aos bancos escolares, uma vez que o sistema escolar tem sido o principal vetor responsável por promover o epistemicídio e o branqueamento das mentes e dos comportamentos. Isso torna os negros responsáveis por não se enquadrarem em padrões e normas apregoados e sustentados pelo nosso sistema educacional.

Contraditoriamente, ao colocar-se em pauta a necessidade de políticas públicas voltadas à reversão desse quadro de apagamento simbólico e quantitativo de negras e negros no ensino brasileiro, vê-se levantar um discurso que defende a meritocracia como critério inalienável para inserção e manutenção de contingentes e conteúdos nas instâncias de ensino, sobretudo no que toca a etapa mais valorizada em nossa sociedade, o ensino superior. Se, por um lado, a noção de meritocracia isola os sujeitos de seu quadro social e os traduz em medidas de desempenho nos processos avaliativos e, por outro, o histórico de discriminações é, simplesmente, desconsiderado como fator que poderia resultar em performances aquém do patamar desejado, é importante colocar sob suspeita o caráter realmente inclusivo de programas de ensino e aprendizagem que se sustentem pela perspectiva do mérito individual 
(Santos; Scopinho, 2016). Mais que isso, é preciso que questionemos os modos pelos quais essa noção que não se sustenta científica, política e socialmente ainda se faz tão presente nas representações que determinam quem devem ser os sujeitos do saber e os saberes considerados válidos.

A dificuldade de colocar em debate e desvelar as variáveis que interferem na organização dos programas oficiais de ensino e o consequente silenciamento sobre temas e conteúdos negros é orquestrada por uma zona muda, que em grande medida é sustentada pelo epistemicídio: os sujeitos são educados/treinados para desconhecerem o lugar de conhecimento e produção de ideias dado a partir de vieses negro e africano. Isto é, dado que epistemologias negras são negadas nos currículos oficiais, não é colocada para negras, negros e demais sujeitos a possibilidade de conhecer o mundo e suas organizações e engendramentos partindo-se de uma posição de sujeito cognoscente negro, ou a partir de uma afroperspectiva (Noguera, 2011a; 2011b).

Como discute Silva (2010, p. 101-102):

É através do vínculo entre conhecimento, identidade e poder que os temas da raça e da etnia ganham lugar na teoria curricular. $\mathrm{O}$ texto curricular, entendido aqui de forma ampla - o livro didático e paradidático, as lições orais, as orientações curriculares oficiais, os rituais escolares, as datas festivas e comemorativas - está recheado de narrativas nacionais, étnicas e raciais. Em geral, essas narrativas celebram os mitos da origem nacional, confirmam o privilégio das identidades dominantes e tratam as identidades dominadas como exóticas ou folclóricas. Em termos de representação racial o texto curricular conserva, de forma evidente, as marcas da herança colonial. O currículo é, sem dúvida, entre outras coisas, um texto racial. A questão da raça e da etnia não é simplesmente um 'tema transversal': ela é uma questão central de conhecimento, poder e identidade. $\mathrm{O}$ conhecimento sobre raça e etnia incorporado no currículo não pode ser separado daquilo que as crianças e os jovens se tornarão enquanto seres sociais. A questão torna-se, então: como desconstruir o texto racial do currículo, como questionar as narrativas hegemônicas de identidades que constituem o currículo?

Diante do exposto, a proposição da inserção de conteúdos de História e Cultura Afro-brasileira no contexto escolar tem por intuito apresentar ao alunado da rede de ensino brasileira a possibilidade de ampliação dos horizontes de contemplação e produção de conhecimento. Contudo, o quadro instalado dificulta a apropriação e operacionalização desta medida nos projetos político-pedagógicos e nos programas oficiais que embasam o fazer em sala de aula. 


\section{A Difícil Tarefa de Implementar a Lei no 10.639/03: o embate à zona muda}

A lei no 10.639/03 (Brasil, 2003) é uma medida planejada para oferecer intervenções pedagógicas que contemplem elementos históricos e culturais de matriz africana para ampliar o leque de ferramentas por meio do qual é possível operacionalizar compreensões de mundo. Mais de uma década depois de sua promulgação e o debate acerca da urgência de implementar um programa efetivamente construído a partir dos propósitos desta lei ainda ressoa.

Tendo em vista analisar e qualificar o processo de implementação da lei, estudos têm sido conduzidos (Souza; Croso, 2007; Mota, 2009; Jesus; Miranda, 2012; Silva et al., 2012; Guedes; Nunes; Andrade, 2013; Silva; Pereira Filho, 2013; Silva, 2014) com intuito de demonstrar os caminhos percorridos pelas instituições e agentes envolvidos na aplicação e monitoramento da lei. Dessa forma, com base nos principais achados nos estudos conduzidos pelos pesquisadores mencionados acima, far-se-á na sequência a apresentação de uma síntese dos desafios, ganhos e controvérsias até então implicados na dinâmica de inserção de agendas voltadas para o trabalho da temática étnico-racial na rede de ensino escolar brasileira.

Tais estudos percorreram localidades situadas em todo o Brasil, com ênfase para os estados do Rio Grande do Sul (RS), São Paulo (SP), Rio de Janeiro (RJ) e Minas Gerais (MG). Os levantamentos foram realizados com diretoras(es), orientadoras(es) educacionais, funcionárias(os) escolares (cozinheiras, bibliotecárias etc.), professoras(es) e estudantes. As pesquisas, de modo geral, buscaram apontar e discutir: I) o conhecimento que as equipes escolares apresentavam sobre a lei; II) a disponibilidade e variedade de materiais pedagógicos para abordar os conteúdos temáticos apregoados pela lei; III) a disposição para ensinar e aprender História e Cultura Afro-brasileiras; IV) a frequência de escolas que desenvolviam trabalhos que contemplassem os objetivos legais; e V) as dificuldades e possibilidades de aplicação dos requisitos da lei.

Assim, a seguir serão apresentados e debatidos os elementos apontados pelos estudos - já discriminados - como fatores que facilitam ou dificultam a criação de condições para a aplicação da lei, entendendo-se que todos os itens elencados acima perpassam a capacidade de sua implementação, podendo atuar como facilitadores ou dificultadores do processo. Cabe ressaltar que se trata de um recorte feito para fins de problematização da inserção e aprofundamento de conteúdos de matriz africana no espaço escolar, de modo que se aponta ser a realidade mais complexa do que a exposição que se pretende realizar neste estudo.

\section{Fatores Dificultadores}

Ainda que as equipes escolares consultadas pelos diferentes estudos relatem conhecer a lei, saber o teor de suas prescrições e tam- 
bém seu caráter obrigatório, nota-se que o desconhecimento teórico e epistemológico sobre a dinâmica das relações étnico-raciais, bem como acerca de conteúdos específicos sobre fatos, histórias, conceitos, descobertas e avanços tecnológicos dados a partir de uma matriz afro-brasileira constitui um quadro que impede que a implementação da lei avance para além de marcos e discussões pontuais. $\mathrm{O}$ desconhecimento acerca dos conteúdos específicos está vinculado à falta de formação básica dos professores e demais membros das equipes escolares para preencherem tais lacunas com dados e entendimentos das culturas, línguas, histórias e costumes africanos e afro-brasileiros que compõem direta ou indiretamente nossa organização social e nossas práticas cotidianas, mas que somos impedidos de (re)conhecer devido ao fato de sermos levados a conhecer e reconhecer o mundo a partir de um prisma eurocêntrico que, no limite, refuta a validade de outras formas de conhecimento e práticas (Souza; Croso, 2007; Jesus; Miranda, 2012; Guedes; Nunes; Andrade, 2013).

Ainda que nos últimos anos se tenha observado o avultamento de propostas e agendas voltadas para desenvolver a formação dos profissionais da educação acerca da educação das relações étnico-raciais e programas de ensino que visem a valorização da diversidade cultural e étnico-racial brasileira, as iniciativas ainda são escassas diante da demanda posta para que esses profissionais, de fato, apropriem-se das temáticas e objetos a partir de uma epistemologia afro-brasileira ${ }^{2}$. Deve-se, ainda, considerar que mais que apreender história, cultura, manifestações e costumes de matriz africana é necessário conjugar tais informações com as disciplinas específicas que compõem as grades dos diferentes níveis da escolarização. Ou seja, ainda que a lei proponha o trabalho "[...] em especial nas áreas de Educação Artística, de Literatura e História Brasileiras” (Brasil, 2003, art. 26-A, parágrafo 20), é preciso haver a transversalização desses saberes nas diversas disciplinas que compõem o currículo. Portanto, é altamente desejável que em Matemática, Química, Geografia, Biologia, etc. contemplem-se conhecimentos e aspectos oriundos das culturas africanas e afro-brasileira. No entanto, é preciso ponderar que essa transversalização pode, no decurso do trabalho cotidiano e dados os entraves discutidos neste texto, incorrer em debates não aprofundados ou pontuais, quando existentes e garantidos. Assim, disciplinas específicas para o trabalho aprofundado e ampliado da temática étnico-racial, se somadas à transversalização, podem gerar resultados mais promissores no que toca à educação das relações étnico-raciais. Obviamente, que, para isso, há necessidade de investimento em formação de professores e recursos pedagógicos adequados para que os profissionais possam desenvolver tais programas de forma adequada e efetiva.

Contudo, observa-se que há por parte de professores e outros profissionais da educação discursos e iniciativas de contestação em relação à validade de uma lei que impõe o trabalho de repertórios oriundos de matrizes africana e afro-brasileira ou a não consideração deste como prioritário. Alega-se que um trabalho desta natureza deveria ser

958 Educação \& Realidade, Porto Alegre, v. 43, n. 3, p. 949-967, jul./set. 2018. 
efetivado a partir das afinidades dos educadores com tais temáticas e agendas, de modo que ao educador deveria garantir-se autonomia para decidir trabalhar com conteúdos a partir de uma afroperspectiva e quando fazê-lo. Entende-se que a dificuldade em aceitar e referendar as proposições da lei como medida alternativa que deve ser sistematicamente observada assenta-se em uma dupla negativa acerca dos saberes advindos de negros (Mota, 2009; Jesus; Miranda, 2012; Silva et al., 2012; Guedes; Nunes; Andrade, 2013; Silva; Pereira Filho, 2013; Silva, 2014).

Por um lado, há o encobrimento ou a não detecção do viés eurocêntrico e embranquecedor que prevaleceu durante muito tempo e que ainda permanece nos currículos oficiais. Uma vez imersos numa epistemologia eurocêntrica e pretensamente universal, deslocarmo-nos desse lugar de sujeito cognoscente orientado eurocentricamente para analisar criticamente as lentes que utilizamos para ler o mundo e, então, contemplar outras óticas e ângulos de visão é um desafio que se coloca. Por outro lado, diante de uma prática de hierarquização de conhecimentos, há a subvalorização de África como possível epicentro de saberes importantes e que possam contribuir para a educação de nossa sociedade e para a produção de Ciência.

Diante desse quadro, é preciso questionar a que propósitos serve a noção de universal, posto que tal concepção tem sido historicamente utilizada para mascarar os vieses que orientam nossa produção de conhecimentos. Centrar-se, portanto, num universo não implica contemplar os demais. Como Ramose (2011) e Nogueira (2012) apontam, apresentar uma única versão de fatos e histórias é um risco, pois empobrece, se não limita, nossas possibilidades de contemplar a existência de versões outras, assim como também é salientado por Chimamanda Ngozi Adichie em seu discurso The Danger of a Single Story (Adichie, 2009), no qual a escritora explora as limitações impostas por experiências que disponibilizam uma única faceta de fatos, acontecimentos, personalidades, teorias etc. de modo a limitar drasticamente o alcance da contemplação do sujeito cognoscente. Dessa forma, os autores advogam a pluriversalidade de conhecimentos, questão que corrobora a necessidade de inserção de conteúdos de matriz afro-brasileira nos programas educacionais oficiais para os distintos níveis de ensino.

Deve-se pontuar o papel exercido pela comunidade na manutenção dos entraves para o trabalho com questões que remetam à África. Paira o entendimento de que sejam conteúdos menos importantes por não capacitarem os estudantes para questões concretas, numa apreensão que entende tais conteúdos e estratégias de intervenção educacional como recreativistas e, assim, não essenciais. Por fim, a intolerância religiosa é um dos fatores que mais atrasam o processo de inserção e difusão de temas e práticas que se referem à África. Identifica-se, assim, a resistência por parte da comunidade em legitimar o exercício de introdução de tais conteúdos por temer a abordagem de questões que possam vincular-se a religiões de matriz africana. 


\title{
Fatores Facilitadores
}

As questões que mais aparecem como facilitadoras neste contexto são as parcerias estabelecidas com os Núcleos de Estudos Afro-brasileiros (NEABs), com Organizações Não Governamentais (ONGs), com organizações do Movimento Negro e demais grupos culturais (Souza; Croso, 2007; Carreira; Silva, 2016). Entende-se que tais parcerias são facilitadoras tanto para o planejamento e execução de agendas de ensino no interior das próprias escolas junto com os educadores, quanto para programar e executar pautas de formação para professores e demais profissionais que compõem as equipes escolares. Dessa forma, a necessidade de estabelecimento dessas parcerias está ligada em grande medida às questões dificultadoras listadas acima. Uma vez que os repertórios acumulados pelas próprias equipes educacionais acerca dos temas previstos na lei estão, muitas vezes, aquém do que seria considerado ideal, os saberes sistematizados por grupos e entidades afro-brasileiros vêm suprir esta lacuna.

No que toca à formação superior dos profissionais que atuam ou atuarão nas instituições escolares, cabe ressaltar o que é estipulado pela Resolução no 1/2004 CNE/CP (Brasil, 2004, art. 1, parágrafo 1º) acerca do papel formador das universidades:

\begin{abstract}
As Instituições de Ensino Superior incluirão nos conteúdos das disciplinas e atividades curriculares dos cursos que ministram, a Educação das Relações Étnico-Raciais, bem como o tratamento de questões e temáticas que dizem respeito aos afrodescendentes nos termos explicitados no Parecer CNE/CP 03/2004.
\end{abstract}

A implementação desta medida somada às parcerias das universidades com as escolas de ensinos Fundamental e Médio, bem como com as entidades do Movimento Negro e das organizações não governamentais (ONGs) deve contribuir para a superação dos descompassos existentes entre as demandas escolares para a proposição e execução de currículos coerentes em termos do tratamento das contribuições dos povos afro-brasileiros e africanos e a escassez de profissionais qualificados para conduzir tais debates. Cabe sublinhar que o dado acima explicitado apenas reforça a ideia de que excelência acadêmica e responsabilidade social são duas facetas de uma mesma moeda e, portanto, devem ser igualmente vislumbradas e fomentadas nas instituições de ensino superior brasileiras.

Além disso, outro fator apontado como positivo para a aplicação da lei é o esforço empreendido por alguns profissionais especificamente em organizar e efetivar projetos, cursos e demais iniciativas que tangenciem ou abordem deliberadamente a temática racial e afro-brasileira. Contudo, é preciso que se tome com cautela tal valorização, para que não se individualize o trabalho que deve ser sistemático e transversal e não dado por trajetórias solitárias que nadem contra as correntes majoritárias no contexto escolar.

960 Educação \& Realidade, Porto Alegre, v. 43, n. 3, p. 949-967, jul./set. 2018. 


\section{Das Controvérsias}

Mesmo quando afirma-se haver o suporte de recursos didáticos (como livros, audiovisuais, jogos etc.) voltados às temáticas afro-brasileiras, eles não aparecem como elementos decisivos para o trabalho junto aos estudantes. É importante, assim, ponderar que a mera presença de livros, filmes e demais recursos não é em si capital para o trabalho adequado sobre a temática em sala de aula. É necessário que o corpo docente e demais profissionais se apropriem destes recursos; saibam sobre sua existência, suas propostas e recortes, de modo a conseguir aplicá-los em suas metodologias de ensino.

Os Projetos Político-Pedagógicos são instâncias em que se decide a agenda e a destinação de recursos que serão aplicados em determinada instituição escolar em certo período. Dessa forma, entende-se que este seria um âmbito imprescindível a ser disputado para fazer valer as medidas a serem aplicadas para implementação da lei. No entanto, este elemento não tem sido mencionado como fator que contribui para tal finalidade e, pelo contrário, é, por vezes, mencionado justamente por engessar as possibilidades de execução de medidas voltadas à valorização de História e Cultura Afro-brasileira.

É interessante notar que entre as parcerias mencionadas como potencializadoras do trabalho para a implementção da legislação em discussão não se destaca o poder público. Isso evidencia que seu papel de catalisador e fiscalizador da implementação de conteúdos de matriz africana não tem sido, de fato, cumprido, o que favorece o não comprometimento das instituições escolares com a efetivação da lei.

\section{Considerações Finais}

Uma concepção de currículo e de proposta pedagógica que nega a diversidade tem consequências devastadoras para a comunidade escolar, em especial para aqueles sujeitos cuja existência é atravessada pelos traços de sua outridade. Suas possibilidades de leitura do mundo ficam, então, limitadas e seus processos de subjetivação são igualmente interpelados, de modo a haver efeitos degenerativos, se não deletérios. Para que haja alterações no quadro identificado, é fundamental que tanto o currículo quanto a proposta pedagógica sejam construídos tendo em vista contemplar a riqueza de conhecimentos e prismas epistemológicos que reside em nossa diversidade cultural. Assim, a construção do Projeto Político-Pedagógico deve ser feita por todos os recursos humanos da escola e da comunidade permitindo reflexões, análises e discussões acerca das necessidades e da realidade social, que futuramente serão expressas nas atividades pedagógicas e didáticas que nortearão as ações da escola para que sejam alcançados os objetivos propostos (Libâneo, 1996) e a transformação social (Pimenta, 1995).

A despeito de haver legislação específica que prevê o desenvolvimento de conteúdos de História e Cultura Africana e Afro-brasileira nas instituições escolares do país, é possível notar que as iniciativas e 
medidas aplicadas para a promoção da educação das relações étnico-raciais permanecem sendo em sua maioria protagonizadas quase exclusivamente por propostas e estratégias dos movimentos negros e/ou sujeitos negros que reconhecem a necessidade de se trabalhar a temática étnico-racial.

Todavia, como oportunamente discute Silva Junior (2002), é possível considerar que este país tem assistido a um fenômeno sem precedentes nos âmbitos político e jurídico nacionais: a progressiva proposição de legislações que visam combater as desigualdades étnico-raciais e, paralelamente, um crescente movimento de judicialização de tais debates, isto é, percebe-se o aumento de demandas populares encaminhadas para o Poder Judiciário, pautadas pelo objetivo de fazer valer direitos anunciados formalmente, mas ineficazes no cotidiano. Exemplo disso nos é dado por Silva (2016) ao expor a existência de um processo em curso, no município do Rio de Janeiro, a partir do qual uma juíza da 12a Vara da Fazenda Pública, determinou em resposta a uma ação movida por entidades do Movimento Negro, a apresentação dos currículos das 10 maiores escolas particulares do Rio de Janeiro, bem como das redes estadual e municipal da capital, para realização de perícia judicial nos mesmos e verificação do cumprimento da lei no 10.639/2003. Percebe-se, segundo os autores, a mobilização dos estabelecimentos de ensino da rede privada em direção ao cumprimento da lei.

Silva (2016) menciona também o Termo de Ajustamento de Conduta (TAC) firmado entre o Ministério Público Federal (MPF) e 11 municípios do interior de São Paulo, com vistas a garantir a introdução do ensino de História e Cultura Afro-brasileiras no sistema curricular das escolas municipais. O TAC foi resultado de uma representação ingressada pelo CEERT no MPF, em 2006, para que as prefeituras dos respectivos municípios, situados na região central do estado, atendessem ao disposto na lei. O que se evidencia, portanto, é que a mera proposição da lei não garante o cumprimento da inserção dos conteúdos previstos nos currículos e trabalhos escolares, no entanto, este pode e tem sido um instrumento importante por meio do qual a sociedade civil tem se organizado e reivindicado o cumprimento dos termos estipulados naquele dispositivo legal.

Cumpre também notar a urgência para que os profissionais de educação reconheçam a existência e as metas prescritas na lei no $10.639 / 03$, numa perspectiva macro. Assim, é possível dizer que eles sabem qual o horizonte prático desta medida (inserção de conteúdos de matriz afro-brasileira) e, portanto, reconhecem o que se vislumbra como ponto de chegada. Mas, o que fazer no caminho até lá e como, numa perspectiva micro (com quais repertórios, materiais e estratégias), é que ainda não se conseguiu definir com sustentação. Assim, o desafio da educação das relações étnico-raciais é pensar currículo e proposta político-pedagógica, compreendendo que o processo de ensino-aprendizagem se dá todos os dias na prática, materializado no jeito de fazer e na garantia ao direito à memória, à história e a conhecimentos significativos para negros e brancos e para outros grupos sociais (Carreira, 2013). 
Tem-se, então, a importância de compreender que o enfrentamento do racismo, do sexismo, da homofobia e de outras tantas discriminações não se dá em um passe de mágica. Nem tampouco, encapsulando as discussões e abordagens em dias comemorativos específicos. Trata-se de enfrentar mais de quinhentos anos de contação de uma única versão dos fatos e histórias. Logo, é preciso compreender e incorporar as resistências e os processos de luta por direitos, protagonizados por sujeitos historicamente marginalizados nos currículos oficiais.

O conjunto de dados levantados indica que ainda é baixo o grau de institucionalização alcançado pela lei no $10.639 / 03$. Partilhamos a concepção de Jesus e Miranda (2012) de que estamos diante de um processo de implantação desta lei e ainda distante da sua necessária implementação. Isto é, aponta-se tratar de um nível ainda incipiente de estabelecimento e enraizamento de tal lei.

Todavia, é preciso reconhecer que a lei não possui a capacidade de mudar de maneira instantânea uma realidade que é histórica e tão arraigada em nossas práticas e imaginário. Porém, por meio dela, é possível criar mecanismos e processos de reflexão que deverão promover a sensibilização e a conscientização dos envolvidos, considerando que o respeito às diferenças exige a diversidade de narrativas, de lógicas e epistemologias no currículo (Noguera, 2012). Isto significa que a reconstrução ou reinvenção de uma política confrontacional, ou seja, de embate diante dos silenciamentos e invisibilizações, no campo da educação exige uma transformação epistemológica. Um novo, polifônico sistema educacional pode emergir à medida em que se pleiteia e se aplica conteúdos outros (Santos; Guilherme; Dietz, 2016).

Por fim, propomos, então, expandir a explicação dos porquês da ausência negra nos bancos escolares para além das questões de vulnerabilidades sociais, assim como das dificuldades de implementação da lei citada para além de escassez de recursos e investimentos humanos e financeiros: ambas as questões respondem às práticas de extermínio da possibilidade de ser o negro sujeito de conhecimento, por meio das investidas do epistemicídio e, portanto, a aplicação de uma lógica pluriversal em nossos sistemas educacionais é um horizonte que urge tanto quanto as reivindicações de sujeitos e movimentos historicamente marginalizados, que pleiteiam a democratização e a expansão das fronteiras e discursos oficiais de produção de conhecimentos.

Recebido em 09 de junho de 2016 Aprovado em 19 de janeiro de 2018

\section{Notas}

1 Neste texto utilizamos a expressão étnico-racial para atender às expressões e aos processos de construção de diferenças, identificações, lugares e direitos sociais com base tanto nas características epidérmico-morfológicas, nas proposições ideológicas e políticas, assim como, nos complexos recortes culturais que diversificam as experiências de negros, brancos, indígenas e 
amarelos, ao passo em que produzem dentro desses mesmos grupos diversidades de trajetórias e identidades. Salientamos também que, assim como alertou Munanga (2000), a utilização dos conceitos de raça ou etnia, de um detrimento do outro, ou mesmo da junção de ambos deve vir acompanhada do apontamento de que em qualquer destes arranjos temos como base uma estrutura racista que se utilizada de diferentes e renovadas estratégias para influenciar as experiências dos diferentes grupos e sujeitos marcados pelas diferenças ditas étnicas e raciais.

2 A expressão epistemologia afro-brasileira refere-se aqui às reflexões, teorias e arcabouços de saberes e cosmovisões organizados por povos afro-brasileiros e que são, em sua maioria, omitidos ou sub-representados nas instâncias oficiais de transmissão de conhecimentos.

\section{Referências}

ADICHIE, Chimamanda Ngozi. The Danger of a Single Story (TED Conferences). 2009. (vídeo). Disponível em: < https://www.ted.com/talks/chimamanda_adichie_the_danger_of_a_single_story/transcript>. Acesso em: 10 jan. 2018.

BRASIL. Conselho Nacional da Educação. Resolução no 1, de 17 de junho de 2004. Institui Diretrizes Curriculares Nacionais para a Educação das Relações Étnico-Raciais e para o Ensino de História e Cultura Afro-Brasileira e Africana. Diário Oficial da União, Brasília, 22 jun. 2004. Disponível em: <http://portal. mec.gov.br/cne/arquivos/pdf/res012004.pdf>. Acesso em: 15 dez. 2017

BRASIL. Lei no 12.288, de 20 de julho de 2010. Institui o Estatuto da Igualdade Racial; altera as Leis nos 7.716, de 5 de janeiro de 1989, 9.029, de 13 de abril de 1995, 7.347, de 24 de julho de 1985, e 10.778, de 24 de novembro de 2003. Diário Oficial da União, Brasília, 21 jul. 2010. Disponível em: <http://www.planalto. gov.br/ccivil_03/_Ato2007-2010/2010/Lei/L12288.htm>. Acesso em: 01 jun. 2016. BRASIL. Lei no 12.711, de 29 de agosto de 2012. Dispõe sobre o ingresso nas universidades federais e nas instituições federais de ensino técnico de nível médio e dá outras providências. Diário Oficial da União, Brasília, 30 ago. 2012. Disponível em: <http://www.planalto.gov.br/ccivil_03/_ato2011-2014/2012/lei/ 112711.htm>. Acesso em: 01 jun. 2016.

BRASIL. Lei $\mathrm{n}^{\circ}$ 10.639, de 9 de janeiro de 2003. Altera a Lei no 9.394, de 20 de dezembro de 1996, que estabelece as diretrizes e bases da educação nacional, para incluir no currículo oficial da Rede de Ensino a obrigatoriedade da temática 'História e Cultura Afro-Brasileira', e dá outras providências. Diário Oficial da União, Brasília, 10 jan. 2003. Disponível em: <http://www.planalto.gov.br/ ccivil_03/leis/2003/L10.639.htm>. Acesso em: 01 jun. 2016.

CARREIRA, Denise. Indicadores da Qualidade na Educação: relações raciais na escola. São Paulo: Ação Educativa, 2013.

CARREIRA, Denise; SILVA, Allyne Andrade e (Org.). Educação das Relações Raciais: balanços e desafios da implementação da lei 10639/2003. São Paulo: Ação Educativa, 2016.

CONTINS, Marcia; SANT'ANA, Luiz Carlos. O Movimento Negro e a Questão da Ação Afirmativa. Estudos Feministas, Florianópolis, v. 4, n. 1, p. 209-220, 1996. Disponível em: <https://periodicos.ufsc.br/index.php/ref/article/view/16670>. Acesso em: 23 fev. 2016. 
DOMINGUES, Petrônio. Um 'Templo de Luz': a frente negra brasileira (19311937) e a questão da educação. Revista Brasileira de Educação, Rio de Janeiro, v. 13, n. 39, p. 517-534, 2008.

FERNANDES, Florestan. A Integração do Negro na Sociedade de Classes. 3. ed. São Paulo: Ática, 1978.

GONÇALVES, Luiz Alberto Oliveira; SILVA, Petronilha Beatriz Gonçalves. Movimento Negro e Educação. Revista Brasileira de Educação, Rio de Janeiro, n. 15, p. 134-158, set./dez. 2000. Disponível em: <http://www.scielo.br/pdf/rbedu/ n15/n15a09.pdf>. Acesso em: 10 jan. 2016.

GUEDES, Elocir; NUNES, Pâmela; ANDRADE, Tatiane de. O Uso da Lei 10.639/03 em Sala de Aula. Revista Latino-Americana de História, São Leopoldo, v. 2, n. 6, p. 421-430. ago. 2013.

INSTITUTO BRASILEIRO DE GEOGRAFIA E ESTATÍSTICA. Censo Demográfico 2000: características da população. Rio de Janeiro: IBGE, 2000.

INSTITUTO BRASILEIRO DE GEOGRAFIA E ESTATÍSTICA. Censo Escolar de Educação Básica. Brasília: INEP/MEC, 2014.

INSTITUTO BRASILEIRO DE GEOGRAFIA E ESTATÍSTICA. Síntese de Indicadores Sociais 2004. Estudos e Pesquisas, Rio de Janeiro, n. 15, 2005.

JESUS, Rodrigo Ednilson de; MIRANDA, Shirley Aparecida de. O Processo de Institucionalização da Lei no 10.639/03. In: GOMES, Nilma Lino (Org.). Práticas Pedagógicas de Trabalho com Relações Étnico-Raciais na Escola na Perspectiva da Lei no 10.639/03. Brasília: MEC; Unesco, 2012. P. 49-70.

LIBÂNEO, José Carlos. Organização e Gestão da Escola: teoria e prática. Goiás: Alternativa, 1996.

MOTA, Edimilson Antônio. O Olhar dos Agentes Escolares sobre a Lei 10.639/03: o desafio de sua implementação. 2009. 135 f. Dissertação (Mestrado em Políticas Sociais) - Universidade Estadual do Norte Fluminense Darcy Ribeiro, Campos dos Goytacazes, 2009.

MUNANGA,Kabengele.UmaAbordagemConceitualdasNoçõesdeRaça,Racismo, Identidade e Etnia. In: BRANDÃO, André Augusto Pereira. Programa de Educação sobre o Negro na Sociedade Brasileira. Niterói: EdUFF, 2000. P. 16-34.

NERY, Maria da Penha. Afetividade Intergrupal, Política Afirmativa e Sistema de Cotas para Negros. 2008. 243 f. Tese (Doutorado em Psicologia) - Programa de Pós-Graduação em Psicologia Clínica e Cultura, Instituto de Psicologia, Universidade de Brasília, Brasília, 2008.

NOGUERA, Renato. Denegrindo a Filosofia: o pensamento como coreografia de conceitos afroperspectivista. Griot - Revista de Filosofia, Cruz das Almas, v. 4, n. 2, 2011a.

NOGUERA, Renato. O Ensino de Filosofia e a Lei 10.639/03. Rio de Janeiro: CEAP, 2011b.

NOGUERA, Renato. Denegrindo a Educação: um ensaio filosófico para uma pedagogia da pluriversalidade. Revista Sul-Americana de Filosofia e Educação, Brasília, n. 18, p. 62-73, 2012.

PIMENTA, Selma Garrido. O Estágio na Formação de Professores: unidade teoria e prática?. 2. ed. São Paulo: Cortez, 1995.

ROSEMBERG, Fúlvia. Relações Raciais e Rendimento Escolar. Cadernos de Pesquisa, São Paulo, n. 63, p. 19-23, nov. 1987. 
ROSEMBERG, Fúlvia. Segregação Espacial na Escola Paulista. Estudos Afro-Asiáticos, São Paulo, n. 19, p. 97-108, 1990.

ROSEMBERG, Fúlvia. Raça e Educação Inicial. Cadernos de Pesquisa, São Paulo, n. 77, p. 25-34, maio 1991.

ROSEMBERG, Fúlvia. Educação Infantil, Classe, Raça e Gênero: notas preliminares. São Paulo: Fundação Carlos Chagas, 1995.

ROSEMBERG, Fúlvia; PINTO, Regina, NEGRÃO, Esmeralda. Diagnóstico sobre a Situação Educacional de Negros (Pretos e Pardos) no Estado de São Paulo. São Paulo: Fundação Carlos Chagas, 1986.

ROSEMBERG, Fúlvia; PINTO, Regina. Raça Negra e Educação. Cadernos de Pesquisa, São Paulo, n. 63, nov. 1987.

ROSEMBERG, Fúlvia; PINTO, Regina. Criança Pequena e Raça na PNAD 87. Textos FCC, São Paulo, n. 13, p. 6-102, 1997.

SANTOS, Boaventura de Sousa. Pela Mão de Alice: o social e o político na pós-modernidade. Campinas: Cortez, 1996.

SANTOS, Boaventura de Sousa; GUILHERME, Manuela; DIETZ, Gunther. Da Universidade à Pluriversidade: reflexões sobre o presente e o futuro do ensino superior. Revista Lusófona de Educação, Lisboa, v. 31, n. 31, p. 201-212, fev. 2016. Disponível em: <http://revistas.ulusofona.pt/index.php/rleducacao/article/ view/5388/3408>. Acesso em: 30 maio 2016.

SANTOS, Elisabete Figueroa dos; SCOPINHO. Rosemeire Aparecida. Desigualdades Raciais, Mérito e Excelência Acadêmica: representações sociais em disputa. Psicologia: Ciência e Profissão, Brasília, v. 36, n. 2, p. 1-13, 2016.

SILVA JUNIOR, Hédio. Discriminação Racial nas Escolas: entre a lei e as práticas sociais. Brasília: UNESCO, 2002.

SILVA, Ádria Paulino da; PEREIRA FILHO, Ednaldo. A Lei 10.639/03 na Compreensão de Professores de Educação Física: estudo de caso da escola municipal de São Leopoldo/RS. Identidade!, São Leopoldo, v. 18 n. 3, p. 279-290, 2013.

SILVA, Allyne Andrade e. Justiça e Educação das Relações Raciais: possíveis contribuições do sistema de justiça para a efetivação da lei 10.639/2003. In: CARREIRA, Denise; SILVA, Allyne Andrade e (Org.). Educação das Relações Raciais: balanços e desafios da implementação da lei 10.639/2003. São Paulo: Ação Educativa, 2016. P. 120-155.

SILVA, Cristiane Ruth Machado et al. Uma Análise Pedagógica sobre a Implementação da Lei n. 10.639/03 em Escolas da Rede Pública e Privada de Belo Horizonte. Pedagogia Em Ação, Belo Horizonte, v. 2, n. 1, p. 61-68, 2012. Disponível em: <http://periodicos.pucminas.br/index.php/pedagogiacao/article/ view/4483>. Acesso em: 03 jun. 2016.

SILVA, Teresa Raquel. A Afrodescendência nas Investigações Científicas: uma década da implementação da lei 10.639/2003 (2003-2013). Espaço do Currículo, João Pessoa, v. 7, n. 3, p. 522-536, 2014.

SILVA, Tomaz Tadeu da. Documentos de Identidade: uma introdução às teorias de currículo. Belo Horizonte: Autêntica, 2010.

SOUZA, Ana Lucia Silva; CROSO, Camila (Coord.). Igualdade das Relações Étnico-Raciais na Escola: possibilidades e desafios para a implementação da lei no 10.639/2003. São Paulo; Petrópolis: Ação Educativa; CEAFRO; CEERT, 2007.

966 Educação \& Realidade, Porto Alegre, v. 43, n. 3, p. 949-967, jul./set. 2018. 
Elisabete Figueroa dos Santos é psicóloga, mestre e doutora em Psicologia pela Universidade Federal de São Carlos - UFSCar. Professora do Centro Universitário Central Paulista - UNICEP, São Carlos/SP.

E-mail: bete.figueroa@gmail.com

Eliane Aparecida Toledo Pinto é licenciada em Ciências Biológicas pela UNESP/Bauru (1997) e em Pedagogia pela UNINOVE (2010), mestre em Ciências Biológicas pela UNESP/Botucatu (2000), doutora em Química pela UNESP/Araraquara (2005) e em Educação para a Ciência pela UNESP/Bauru (2016). É professora da Fundação Educacional Municipal de Ibitinga/SP e na Universidade do Sagrado Coração em Bauru/SP.

E-mail: elianetol@hotmail.com

Andréia Melanda Chirinéa é graduada em Pedagogia pela Universidade do Sagrado Coração, Especialista em Gestão Escolar. Mestre e Doutora em Educação pela UNESP/Marília na área de Políticas Públicas e Administração da Educação Brasileira, Atualmente, é professora da rede pública municipal de Bauru (SP) e professora universitária.

E-mail: andreia.melanda@gmail.com

Este é um artigo de acesso aberto distribuído sob os termos de uma Licença Creative Commons Atribuição 4.0 Internacional. Disponível em: $<$ http://creativecommons.org/licenses/by/4.0>. 